\title{
¿Cooptación, oportunidades políticas y sentimientos? Las Madres de Plaza de Mayo y el gobierno de Néstor Kirchner
}

\author{
Enrique Andriotti Romanin \\ Universidad Nacional de Mar del Plata, CONICET, Mar del Plata, Argentina. \\ Email: romanin@mdp.edu.ar
}

Resumen: En 2003 resultó electo presidente de Argentina el Dr. Nestor Kirchner. Desde entonces algunas organizaciones del Movimiento de Derechos Humanos comenzaron a acercarse al gobierno que, a su vez, se mostró receptivo a sus demandas. En el trabajo que aquí se presenta se analizan las posiciones de la Asociación Madres de Plaza de Mayo ante el gobierno de Néstor Kirchner, con el objetivo de aproximarnos a comprender los cambios en su relación con el gobierno y el Estado. Para la realización de este trabajo se utilizaron discursos, diarios y revistas argentinas, documentos y entrevistas a miembros de esta organización.

Palabras clave: Derechos humanos, Política, Estado, Gobierno

\section{Cooptation, political opportunities and feelings? The Mothers of Plaza de Mayo and Nestor Kirchner's government $^{1}$}

\begin{abstract}
In 2003 Nestor Kirchner was elected president of Argentina. Since then some organizations of the Human Rights Movement began to approach the government which, in turn, was receptive to their demands. In this essay we state and analyze the positions of the Mothers of Plaza de Mayo towards the government of Nestor Kirchner, aiming to understand the nature of their relationship towards government and the State, and analyze how it changed. To carry out this study we worked with speeches, documents and interviews with members of this organization and sources such as Argentinian newspapers and magazines of national circulation.
\end{abstract}

Key words: Human Rights, Politics, State, Government

\section{Cooptação, oportunidades políticas e sentimentos? As Mães da Plaza de Mayo e o governo de Néstor Kirchner}

Resumo: Em 2003, foi eleito presidente da Argentina, o Dr. Néstor Kirchner. Desde então, algumas organizações do Movimento pelos Direitos Humanos começaram a se aproximar do governo que, por sua vez, mostrou-se receptivo às suas demandas. No trabalho aqui apresentado se analisam as posições das Mães da Plaza de Mayo perante o governo de Néstor Kirchner, a fim de obter uma melhor aproximação para compreender as mudanças em seu relacionamento com o governo 
e o Estado. Para a realização deste trabalho foram utilizados discursos, jornais e revistas argentinas, documentos e entrevistas com membros desta organização.

Palavras-chave: Direitos Humanos, Política, Estado, Governo

\section{Introducción}

El 27 de octubre de 2010 falleció el ex presidente de Argentina Néstor Kirchner. Un día después la presidenta de la Asociación Madres de Plaza de Mayo (en adelante AMDPM), Hebe Pastor de Bonafini dio a conocer una carta abierta donde señaló alguno de los significados que tenía para ella la figura del ex presidente,

[...] Quiero contarte en esta carta que me atreví a pasar el primer día sin vos, con ese vacío que me dejaste y que creía que tardaría en llenar porque cuando desaparecieron mis otros hijos el agujero fue casi eterno. Cuando vos llegaste a mi vida me volvió la alegría, me sentí más fuerte, acompañada, comprendida y respetada, [...], Gracias, hijo, por permitirme vivir junto a vos y tus principios, gracias por vivir con tanta pasión. Estoy orgullosa de vos y de esta juventud que formaste para el proyecto nacional y popular, que es decir la liberación [...] (Hebe de Bonafini, 2010, 28 de octubre)

Las palabras de Bonafini ${ }^{2}$ nos permiten vislumbrar una de las transformaciones operadas en la organización más emblemática del denominado Movimiento de Derechos Humanos de Argentina: su pasaje de acérrima opositora a los distintos gobiernos que se sucedieron tras el retorno a la democracia en 1983, a ferviente aliada del gobierno encabezado por Néstor Kirchner. Esto último, que no ocurrió de la noche a la mañana, constituyó un punto de inflexión en la historia de la Asociación que no ha estado exento de polémicas y las ha situado en el centro del debate político y mediático de la Argentina de los últimos años.

El trabajo que aquí se presenta busca indagar en algunas dimensiones poco exploradas acerca de la vinculación entre la AMDPM y el gobierno de Néstor Kirchner. En particular, se analizan algunos aspectos del significado otorgado por esta al proceso político inaugurado en 2003. El objetivo de este artículo es aportar a la respuesta a una pregunta: ¿por qué motivos y bajo qué condiciones la Asociación Madres de Plaza de Mayo, que históricamente se caracterizó por confrontar con el Estado y los distintos gobiernos de Argentina, protagonizó entre 2003 y 2007 un proceso de creciente vinculación y acompañamiento al gobierno nacional?

Para la realización de este trabajo se utilizaron numerosas fuentes de información primaria, especialmente discursos y documentos de la organización (seleccionados entre la enorme cantidad de material que han produ- 
cido la AMDPM), discursos presidenciales, y fuentes secundarias como diarios y revistas argentinas de circulación nacional.

\section{Las Madres y el Kirchnerismo}

A partir de su aparición, en los albores de la dictadura militar que ocupo el poder en Argentina en marzo de 1976, la AMDPM ocupó un lugar de importancia en la política argentina. Desde entonces los trabajos académicos en torno a la AMDPM son numerosos y abarcan diferentes dimensiones y temas. Solo los últimos años algunas investigaciones se han orientado a comprender las transformaciones recientes de la AMDPM, en especial, a partir de sus vinculaciones con el "Kirchnerismo"2. Un conjunto de trabajos se ha orientado a pensar el vínculo entre la AMDPM y el gobierno de Néstor Kirchner bajo la figura de la cooptación. Para éstos la cooptación de la AMDPM se expresa en la defensa a ultranza de las políticas de este gobierno y se explica por la política selectiva de derechos humanos de Kirchner (Cf. Braslavsky, 2009), por una convergencia de intereses económicos y financieros que llevaron a las Madres a depender del gobierno kirchnerista (Cf. Gasulla, 2012) o por el resultado de un mecanismo prebendario basado en subsidios, retornos y apoyo político (Cf. Romero, 2011). En términos generales estos trabajos comparten la hipótesis de que la Asociación Madres de Plaza de Mayo se ha vuelto un instrumento de los gobiernos "kirchneristas" quienes mediante incentivos de distinto orden habrían logrado reducir su autonomía y capacidad de decisión. De este modo, la cooptación de la AMDPM es visualizada como el resultado de una estrategia del kirchnerismo que logró apropiarse de la bandera de los derechos humanos con el objetivo de lograr una mayor legitimación de sus políticas.

En una línea diferente, otros autores han buscado distanciarse de las perspectivas que proponen pensar el vínculo entre kirchnerismo y la AMDPM como una cooptación a través de explicar su adhesión ideológica a este, a partir de las condiciones de la interpelación que su discurso supuso para Las Madres. Barros ha señalado que el discurso de Kirchner "constituyó una interpelación que funcionó reapropiándose de los sentidos que estructuraban el discurso histórico de Las Madres” (2009: S/P), pero que además le agregó otros elementos discursivos que posibilitaron una identificación de estas con su figura y con las políticas de su gobierno. Para Retamozo (2011) la adhesión al gobierno y sus políticas fue posible en tanto el kirchnerismo elaboró un discurso que ubicó al gobierno en el mismo campo que los movimientos sociales de manera tal que compartían también sus enemigos: el neoliberalismo, el FMI, la dictadura militar, las empresas privatizadas, la clase política corrupta, la justicia ineficiente, las diferentes corporaciones, entre otras. De esta manera absorbió las demandas de verdad, justicia y castigo logrando también el respaldo de la AMDPM (Cf. Retamozo, 2011). Una variante en esta línea es presentada por Morales quien sostiene que la adhesión de la AMDPM al gobierno no puede ser entendida como un sinónimo del éxito de la cooptación kirchnerista sino 
como "parte de un proceso de articulación política contingente que como efecto re significa su lucha” (2012: 61). Para esta autora, la AMDPM no se desplazó de una posición a otra por consecuencia de las maniobras de manipulación y dominación sino porque sus integrantes fueron interpeladas por un discurso que rompió con los distintos gobiernos y sus políticas representando algo que para ellas había estado ausente en los últimos años de vida democrática: la posibilidad de superar el neoliberalismo y lograr justicia. Por último Montero (2013) ha planteado la complejidad del proceso de interpelación del discurso kirchnerista al analizar los tópicos y las cadenas argumentativas de éste. Para la autora el mismo se desplegó mediante dos modos de interpelación diferente, uno ideológico y otro afectivo, que implicó también la construcción de un ethos militante y que fue efectivo a la hora de lograr adhesiones de actores para que acompañaran al gobierno (2013: 288).

Aunque estos trabajos ofrecen pistas sustantivas para comprender la relación entre el kirchnerismo y la AMDPM, la evidencia empírica reciente acerca de esta última sugiere que su adhesión al proyecto inaugurado por Néstor Kirchner en 2003 expresa cambios profundos que permiten ampliar los enfoques centrados en la cooptación o la adhesión ideológica.

Uno de los cambios menos analizados radica en la redefinición de significados, la movilización de emociones y sentimientos que la figura de Néstor Kirchner generó entre las integrantes de la Asociación. En este sentido consideramos que estudiar los significados atribuidos por las integrantes de AMDPM al proceso político inaugurado en 2003 constituye un prisma privilegiado para acercarnos a comprender no solo los cambios en la relación con el Estado por parte de uno de los organismos de derechos humanos más emblemático de América Latina, sino también entender ciertos aspectos acerca de la dinámica histórica de cooperación/confrontación entre movimientos sociales y Estado desde una perspectiva que, de manera complementaria a otras líneas de indagación, privilegie el papel de las emociones, los sentimientos y el significado de la acción para los actores.

La importancia de los significados de la acción ha sido desarrollada ampliamente por algunos autores que han postulado la importancia de pensar los marcos de la acción colectiva (Cf. Gamson, 1992a; Snow y Benford, 1992; Tarrow, 1997) como un producto tanto de los esquemas y sentimientos preexistentes en una población dada como de un trabajo de significación realizado por los promotores de las acciones. Para estos se torna relevante visualizar cómo los integrantes de un movimiento social procesan los cambios de una estructura determinada de oportunidades políticas ${ }^{2}$ y definen los cursos de acción elegidos (Cf. Mac Adam, 1982; Zald, 1999) poniendo en juego significados y sentimientos. De este modo las oportunidades políticas no son solo percibidas y aprovechadas por los actores sino también implican un proceso de creación de nuevas oportunidades y sentidos. Por ende, los cambios de sentido no pueden ser pensados como efectos únicamente de un cambio abrupto de las oportunidades políticas sino más bien como el resultando de un proceso enmarcador (Cf. Gamson, 1992b) 
realizado por un grupo de personas vinculadas a un movimiento social, que propenden por forjar modos compartidos de considerar el mundo $y$, desde ahí, legitimar sus posturas interpretativas de las problemáticas y justificar su acción colectiva. El estudio de los marcos de acción colectiva permite reconocer que estos involucran una serie de significados, creencias y sentimientos orientadores de la acción, que inspiran y legitiman las actividades y campañas del colectivo, de la asociación o del movimiento social. Con todo, distintos autores han señalado la importancia de ampliar estos enfoques e incluir en ellos la dimensión emotiva (Goodwin, Jasper y Poletta, 2000; Gould, 2009). En esta línea Jasper ha señalado que "parte de este esfuerzo por incorporar un amplio rango de significados debemos sumar las emociones a ese aparato cognoscitivo que todas las herramientas de trabajo han intentado adoptar” (2012:35). Nussbaum (Cf. 2001) ha señalado que estudiar las emociones nos ayuda a comprender como los actores dotan al mundo de significado y formulan acciones que respondan a los acontecimientos: una forma de pensar y de evaluar más a menudo y no una fuente de irracionalidad. Consideramos que aunque lo sentimientos y emociones no pueden explicar por si solos los complejos procesos que explican la adhesión a un proyecto político o su rechazo, tampoco deben ser excluidos. Como veremos el componente emotivo/sentimental ha sido una clave para explicar la adhesión de la AMDPM al kirchnerismo.

\section{De la confrontación contra la dictadura militar, a la confrontación con los gobiernos democráticos}

Las Madres de Plaza de Mayo hicieron su aparición pública en abril de 1977 en el momento de mayor intensidad represiva de la última dictadura militar. Si inicialmente sus reivindicaciones, su discurso y sus acciones se habían definido en confrontación con la dictadura militar (D’Alessandro, 1998; Gorini, 2011a) el retorno de la democracia en 1983 significó para ellas nuevos desafíos.

El inició del gobierno de Raúl Alfonsín (1983-1989) encontró a algunas las madres de desaparecidos enroladas en la AMDPM sosteniendo sus demandas de verdad y justicia. Aunque algunas de las integrantes de la asociación se manifestaron esperanzadas con la nueva situación política, las primeras señales del gobierno generaron preocupación entre ellas. Progresivamente, en el transcurso de pocos meses, la AMPDM retomó un rol de oposición que había forjado desde sus inicios durante la última dictadura militar, pero ahora frente a un gobierno electo democráticamente.

Su confrontación con el nuevo gobierno democrático se inició paulatinamente al calor de sus divergencias con las iniciativas gubernamentales acerca de cómo lidiar con el pasado de terrorismo de Estado. Para la AMDPM éstas expresaban la voluntad política del gobierno de limitar el castigo a los responsables militares del terrorismo de Estado por sobre la búsqueda de toda la verdad y justicia. Así la confrontación con el gobierno 
se acentuó con su oposición a los decretos 156/83 y 157/83 que ordenaban en simultaneo la detención de la cúpula de las organizaciones armadas y de los miembros de las tres primeras juntas militares ${ }^{5}$, la creación de una Comisión por la Verdad (la Comisión Nacional sobre la Desaparición de Personas), con la realización del denominado “Juicio a las Juntas Militares”6 y alcanzó su punto máximo tras la sanción de las leyes de Obediencia Debida y Punto Final ${ }^{7}$. Estas leyes que limitaron en la práctica la posibilidad de castigo a los responsables de los crímenes cometidos durante la dictadura militar fueron denunciadas por la AMDPM como la consagración de la impunidad en la Argentina de la cual todos los representantes de los poderes del Estado eran responsables.

Como resultante de esta dinámica de confrontación con el gobierno se produjo la división de la Asociación ${ }^{8}$, la exacerbación de sus diferencias con otros organismos de derechos humanos ${ }^{9}$ y progresivamente tendieron a conformarse como un nucleamiento intensamente político (Gorrini, 2011b:20). A fines de la década de 1980 era claro que sus demandas trascendían ampliamente la búsqueda de verdad y justicia y que su discurso constituía una impugnación a la institucionalidad política que había emergido tras la dictadura militar:

[...] Queridos, el camino regado con vuestra sangre es duro, firme y largo. Y en él seguimos quienes tenemos la pasión de vivir y la pasión de la libertad, mal que les pese a algunos que hoy se han arrepentido de haber creído en la revolución, a otros que ayer nomás eran golpistas y ahora se dicen democráticos, y a ciertos hipócritas que esconden un pasado de complicidad con la dictadura y hoy integran organismos de derechos humanos, [...], Nosotras, como siempre, seguiremos luchando por la vida, contra la muerte, aunque tantos nos quieran hacer creer ahora que este sistema que esclaviza y humilla es el único posible [...] (Asociación Madres de Plaza de Mayo, 1988, 1 de abril)

La llegada al gobierno de Carlos Menem (1989 - 1999) significó para la AMDPM una intensificación de los niveles de confrontación. Las primeras medidas del nuevo gobierno en relación al pasado dictatorial mostraron la combinación de una política de indultos a los responsables del terrorismo de Estado, de reparaciones económicas a las víctimas y ascensos a militares vinculados con la represión y que fueron rechazadas de manera tajante por la AMDPM. A su vez, el impulso de un conjunto de medidas económicas de orden neoliberal condujo a la AMDPM a adoptar posiciones políticas de mayor intransigencia que desembocaron en la identificación de las diferentes políticas implementadas por los gobiernos democráticos como una línea de continuidad que se remontaba hasta la dictadura militar tendiente a garantizar la impunidad y la instalación del modelo neoliberal ${ }^{19}$.

Por entonces, la confrontación con el gobierno de Menem era entendida como la continuidad de la lucha contra la dictadura militar, en la medida 
en que profundizaba el modelo económico neoliberal que se había impuesto con el golpe militar. En este sentido, la continuidad de la demanda de justicia, el esclarecimiento de los crímenes cometidos durante el terrorismo de Estado y el cuestionamiento a la impunidad eran acompañados por una denuncia de los efectos de las políticas neoliberales sobre la democracia en Argentina. Esto último ocupó un lugar cada vez más destacado en el discurso de la AMDPM y daba cuenta de la fuerte politización y radicalización del discurso de las integrantes de la Asociación:

[...]Y la dictadura, la peor dictadura, esa que se llevó lo más hermoso y grande que teníamos que eran nuestros hijos, que se jugaron enteros para conseguir un país mejor, una patria más linda, más justa, más solidaria. Nuestros hijos nos enseñaron que la vida no vale sino vale el otro. Y las Madres aprendimos, [...], Nosotras estamos convencidas que todos ustedes, los que están aquí, ya saben qué pasó y muchos están sufriendo estos planes económicos de hambre. Hoy el capitalismo, los grandes empresarios, las multinacionales -esas que a veces no conocemos-, el Banco Mundial, todos estos haciendo que hoy no nos maten con balas, hoy nos matan de hambre y con enfermedades de la pobreza. [... (Hebe Pastor de Bonafini, 1998, 24 de Marzo)

Por entonces, la sociedad argentina se preparaba para elegir el sucesor de Carlos Menem. Las integrantes de la AMDPM se mostraban escépticas ante la posibilidad de un cambió. Su postura se fundaba en su desazón con todos los gobiernos desde el retorno a la democracia, pero más ampliamente su desconfianza hacia todos los actores políticos institucionales:

[...] Las Madres tenemos mucha memoria, una memoria fértil que se reproduce, que crece, que se agiganta, porque no nos olvidamos de los radicales que golpearon la puerta de los cuarteles para pedirle a los milicos hijos de mil putas que vinieran a salvar la patria. Y no nos olvidamos de los peronistas que firmaron el aniquilamiento del opositor político y que hoy, radicales y peronistas se llenan la boca haciendo marchitas y queriéndole hacer homenajes a nuestros hijos, [...], Los peronistas, porque dejaron que los mejores peronistas murieran, y los mataron ellos y no hicieron nada por ellos, y los radicales porque hicieron las leyes de vergüenza y hoy nos quieren decir que son diferentes. Más de lo mismo compañeros, ¡No! [...] (Hebe Pastor de Bonafini, 1998, 10 de diciembre)

En consonancia la elección del radical Fernando de la Rúa en 1999 fue interpretada por AMDPM como otro eslabón de la continuidad de la política de impunidad. Aunque el nuevo gobierno de la Alianza por el Trabajo, la Justicia y la Educación ${ }^{11}$ se presentó como diferente al anterior y algunos de sus funcionarios estaban identificados con la lucha por los derechos humanos, sus reiteradas negativas a revisar as- 
pectos sustantivos de la política de derechos humanos de las gestiones anteriores y la profundización de políticas económicas y sociales de corte neoliberal situó a la AMDPM en clara oposición al gobierno. Durante los dos años de la presidencia de De la Rua, las integrantes de la AMDPM participaron en numerosos actos de repudio y denuncia de sus políticas, y la movilización que condujo a la salida abrupta del gobierno tras las jornadas del 18 y 19 de diciembre de $2001^{12}$ tuvo en ellas a un actor protagónico.

La designación de Eduardo Duhalde (2002 -2003) fue interpretada por estas como la continuidad de la lucha contra el neoliberalismo y una clara señal de la descomposición del sistema político argentino. Duhalde, quién había sido vicepresidente de la nación durante el primer gobierno de Menem, había polemizado en reiteradas ocasiones con las Madres de la AMDPM y era para éstas la continuidad de la política neoliberal en la Argentina. Al respecto, la AMDPM publicó una carta abierta donde señaló sus discrepancias con el nuevo presidente, pero también con sus antecesores y con la dirigencia política:

[...] Las Madres de Plaza de Mayo estamos asistiendo con angustia, vergüenza, desesperación e impotencia, al peor momento de la historia del hambre de nuestro pueblo. Las Madres no podemos tolerar la indiferencia y la complicidad de la dirigencia política ante tantos crímenes, [...], Nuestros hijos entregaron sus vidas en la lucha contra el plan económico de Martínez de Hoz y Cavallo. El mismo que continuaron luego Alfonsín, Menem, De la Rúa y hoy Duhalde. Nuestros gobernantes entregaron la riqueza del país a los grandes grupos económicos y al Fondo Monetario Internacional, [...], Las Madres de Plaza de Mayo responsabilizamos a todos los que gobiernan del crimen del hambre de nuestros niños. No podemos aceptar que nuestros niños coman sapos rellenos, ratas, comida podrida, caballos enfermos para sobrevivir [...] (Asociación Madres de Plaza de Mayo, 2002, 5 de junio)

En síntesis, desde el retorno democrático las Madres fueron incrementando su oposición política a los diferentes gobiernos que identificaron como una solución de continuidad en tanto garantes de la impunidad y de la injusticia, en simultáneo, de políticas de orden neoliberal. Esto las condujo a elaborar una representación negativa acerca de la institucionalidad política instaurada desde 1983, de la dirigencia política que es considerada como responsable de las reiteradas injusticias, del hambre y la desolación del pueblo argentino. Más ampliamente, la representación del Estado comenzó a ser configurada desde la movilización de un consenso acerca de los abusos, violencia, represión, castigo y crueldad que imperaba en la sociedad argentina (Cf. Mayorga Rogel y del Valle Rojas, 2010). Frente a ello la AMDPM se situó como portadora de un mandato ético innegociable de resistencia y demandaron, como una gran parte de la sociedad argentina, "que se vayan todos"13. 


\section{Kirchner presidente: "el enemigo no está en la casa rosada"}

En abril de 2003 se realizaron elecciones presidenciales en Argentina. En ellas se enfrentaron 18 candidatos y aunque el ex presidente Carlos Menem se impuso con un 24, 45\%, no obtuvo los votos necesarios para ser electo presidente en la primera vuelta ${ }^{14}$. Esto obligó a la realización de una segunda vuelta entre Carlos Menem y el segundo candidato más votado, el ex gobernador de Santa Cruz, Néstor Kirchner quien había cosechado el 22, $24 \%$ de los votos y que era apoyado por el presidente Eduardo Duhalde. Pero esa elección no se realizó: ante la posibilidad cierta de perder Carlos Menem declinó presentarse y resultó electo como nuevo presidente Néstor Kirchner. Esta debilidad electoral de origen marcó un signo distintivo de la nueva gestión que prontamente mostró su intención de diferenciarse de otros candidatos y así ampliar su legitimidad.

En materia de lucha por los Derechos Humanos los antecedentes de Kirchner eran escasos, pero desde el comienzo de su gestión buscó diferenciarse de los gobiernos que lo antecedieron. En su discurso de asunción frente a la Asamblea Legislativa afirmó:

[...] Formo parte de una generación diezmada, castigada con dolorosas ausencias; me sumé a las luchas políticas creyendo en valores y convicciones a las que no pienso dejar en la puerta de entrada de la Casa Rosada. No creo en el axioma de que cuando se gobierna se cambia convicción por pragmatismo. Esto constituye un verdadero ejercicio de hipocresía y cinismo. Soñé toda mi vida que este país se podía cambiar para bien. Llegamos sin rencores, pero con memoria. Memoria no sólo de los errores y horrores del otro, sino también es memoria sobre nuestras propias equivocaciones, [...], vengo a proponerles un sueño que es la construcción de la verdad y la justicia [...] (Néstor Kirchner, 2003, 25 de mayo).

En simultáneo, el nuevo gobierno tomó una serie de medidas tendientes a mostrar su diferencia con las anteriores gestiones presidenciales en relación con los Derechos Humanos. En primer lugar durante la primera semana de su gestión se reunió con los principales referentes de organismos de derechos humanos en varias ocasiones. Asimismo, en una de sus primeras acciones de gobierno Kirchner dispuso el desplazamiento y pase a retiro de militares que habían estado vinculados con la represión. Pocos meses después tomó otra medida concreta de diferenciación derogando el decreto 1581/01 promulgado por el gobierno de Fernando de la Rúa, que impedía las extradiciones de militares involucrados en procesos de lesa humanidad, se pronunció a favor de que la justicia nacional resolviera el destino de cada militar acusado de violar los derechos humanos y promovió la nulidad de las leyes de Obediencia Debida y Punto Final. Esto significó otro cambio concreto respecto a las medidas adoptadas por las anteriores gestiones presidenciales. Así, las medidas adoptadas por el nuevo go- 
bierno generaron un cúmulo de expectativas y la creencia de asistir a un quiebre en la continuidad de la impunidad. En una de sus primeras expresiones públicas Hebe de Bonafini sintetizó la situación al expresar: "es diferente a lo que habíamos creído. Ha empezado a hacer algunas cosas con las que todos estuvimos soñando desde hace mucho tiempo" (Página 12, 2003, 4 de junio).

La característica de "lo diferente" asignada al nuevo presidente expresó algunos de las claves interpretativas intervinientes en la nueva definición de la etapa: la posibilidad de creer y hacer. Esta percepción constituyó la base para una redefinición radical de su experiencia de vinculación con el nuevo gobierno y permitió el reencantamiento de un vínculo con el sistema político que para muchas integrantes de la AMDPM se había roto desde hacía mucho tiempo o directamente nunca había existido ${ }^{15}$. Así, el escepticismo comenzó a ser reemplazado por una nueva esperanza en la política institucional, o al menos en el Poder Ejecutivo. Durante los primeros meses del gobierno de Kirchner, aunque mantuvieron cierta distancia crítica con el gobierno, la AMDPM no perdió ocasión para expresar esta nueva percepción:

[...] Se ha abierto un nuevo espacio para nosotros, una nueva forma de atender a la gente, [...], además, la nulidad de las leyes de Obediencia Debida y Punto Final, todos los cambios en el Ejército y la Policía fueron cosas sorprendentes, igual que la incorporación de (Eugenio) Zaffaroni a la Corte Suprema, son cambios que traen un aire diferente [... ] (Página 12, 2003, 10 de diciembre).

Pero la nueva gestión gubernamental no fue interpretada por la AMDPM como simplemente una oportunidad política de ruptura de la impunidad o como un cambio en sus oportunidades a partir de un diagnostico únicamente político de las acciones de este. Progresivamente, su diagnosción realizada por el presidente Kirchner del pasado militante de la generación de los 70’. Esto último constituyó una novedad del discurso de Kirchner. Un hito en este sentido fue el discurso pronunciado por el presidente Kirchner el 25 de marzo de 2004 con motivo de la cesión a los organismos de derechos humanos de los terrenos del ex Centro Clandestino de Detención de la Escuela de Mecánica de la Armada. En ese acto, Kirchner se dirigió a "las Abuelas, Madres y a los Hijos” y les pidió “perdón de parte del Estado nacional por la vergüenza de haber callado durante 20 años de democracia por tantas atrocidades”. Pero en su discurso presentó también una inscripción de continuidad con los ideales de los jóvenes de los 70’, aquellos que habían sido muertos o asesinados por la dictadura, al apelar a ellos como fundamento de sus políticas

[...] Por eso, sé que desde el cielo, de algún lado, nos están viendo y mirando; sé que se acordarán de aquellos tiempos; sé que por ahí no estuvimos a la altura de la historia, pero seguimos luchando como podemos, con las armas que tenemos, soportando los apretujones y los aprietes que nos puedan hacer. Pero no 
nos van a quebrar, compañeros y compañeras [...] (Néstor Kirchner, 2004, 24 de marzo)

Como ha señalado Jelin "el Presidente habló identificándose como miembro de su grupo político generacional” (2007: 54), resaltando su pertenencia a la generación de militantes que lucharon por una sociedad mejor y situando esto como el motivo por el cual desaparecieron. Pero las referencias a sus compañeros y compañeras que no están se combinaron en su discurso con un reconocimiento a quienes expresaban esa voz: los sobrevivientes y sobre todo, las Madres, las Abuelas y los Hijos de los desaparecidos. De esta forma la orientación de su discurso replicó y reforzó el "familismo" que desde finales de la dictadura situó a los familiares como los legítimos demandantes de verdad y justicia. El impacto del acto y las palabras del presidente se hicieron sentir prontamente entre las madres de la $\mathrm{AMDPM}^{16}$. Aunque habían decidido no participar formalmente en el acto, al día siguiente publicaron una solicitada en uno de los principales diarios del país donde agradecían al Presidente por lo que consideraron "un día histórico" y "por demostrar con sus palabras el amor a nuestros hijos" (Diario Página 12, 2004, 25 de febrero). Pocos días después, Hebe de Bonafini ratificó el nuevo significado que para la AMDPM tenía el proceso político en curso:

[...] Me la pasé diciendo que Menem, Duhalde y Kirchner eran la misma mierda. Y después tuve que ir a decirle: "Señor presidente, me equivoqué, yo dije que usted es la misma mierda que los otros pero no: usted es totalmente distinto". Y se lo reconocí así, sinceramente. Las Madres somos muy libres para decir lo que pensamos. En un discurso, hace años, dije que alguna vez un hijo nuestro iba a cruzar la plaza, y se iba a sentar en el sillón para ser presidente. Y ahora él me contó que el 24 de marzo de 1976 ya empezó a pensar que quería llegar a presidente. Lo que no soñé es que algo así iba a ser tan rápido. [...] (Hebe Pastor de Bonafini, 2004, 2 de abril)

La interpretación respecto de Kirchner como un hijo se convirtió desde entonces para la AMDPM en una clave de lectura de la situación. El vínculo familiar comenzó a ser destacado por las integrantes de la Asociación en reiteradas ocasiones mediante frases como "es uno de los hijos de los 70" o "es uno de nuestros hijos”. En este sentido, su apelación al carácter familiar de Kirchner realizado por las integrantes de la AMDPM expresó la identificación afectiva que estas tenían con él. La invocación de sentimientos como "amor" "lealtad" o "redención” que la figura de Kirchner generó les permitió una reconciliación con la política y operó como una de las condiciones centrales para la aceptación por parte de las integrantes de la AMDPM de las medidas gubernamentales. Desde entonces se produjo una compleja redefinición acerca de la etapa, que las condujo a combinar la idea de una ruptura con la impunidad con la reivindicación de un proyecto histórico identificado con el nuevo gobierno que recuperaba los ideales de la generación de los 70' y que comenzó a ser percibido como una oportunidad que debían aprovechar. Esto último se tradujo en el apoyo al presidente 
Kirchner en diferentes actos donde, como contraparte, este producía un constante reconocimiento de su lugar en la historia: "En el momento más terrible de la noche de la dictadura, fueron hombres y mujeres, pero sobre todo mujeres, las que se organizaron para enfrentar la barbarie. Fueron las Madres y Abuelas de Plaza de Mayo” (Página/12, 25 de marzo de 2006).

En simultáneo se produjo otro cambio en la manera de interpretar el proceso político que acompañó al que mencionamos anteriormente. Como ha señalado Andriotti Romanin este consistió en "una redefinición del lugar asignado al Poder Ejecutivo y, en términos más amplios al Estado” (2012: 51). Si durante la etapa posterior a la sanción de las leyes de Obediencia Debida y Punto Final, el Estado fue situado por la AMDPM como el garante de la impunidad política constituyéndose en su principal antagonista, la interpretación de la situación era ahora bien diferente.

Las nuevas posibilidades de apertura que ofreció el Poder Ejecutivo a la AMDPM, implicaron previamente una redefinición del Estado como un espacio abierto, pero también en disputa. En este aspecto, los cambios operados condujeron a repensar el rol asignado y redefinir uno nuevo. La nueva clave interpretativa acerca del Estado se caracterizó por transcurrir en dos niveles: uno instrumental y otro como posibilidad de construcción. En el primero de los casos, este comenzó a ser interpretado como la posibilidad de nuevos recursos para las tareas y para los organismos, en tanto el apoyo al gobierno nacional garantizaba un acompañamiento económico e institucional en sus iniciativas, nunca antes obtenido; pero también significó vislumbrar al Estado como un espacio de disputa contra los resabios del modelo neoliberal. Esto último, se manifestó en una manera de concebir la vinculación con el Estado como parte de un proyecto político estratégico de largo plazo, desde donde fortalecer la lucha política contra un modelo de país y de sociedad excluyente y represiva, relacionado con la idea de impunidad que para Las Madres por entonces aun constituía una asignatura pendiente.

Así, la nueva interpretación de la etapa combinada con los sentimientos en torno al presidente, condujo a las Madres a redefinir sus objetivos y métodos de lucha. Esto se manifestó en una decisión que marcó un punto de inflexión en la historia de la Asociación: culminar con la realización de la denominada marcha de la resistencia ${ }^{17}$. Hebe de Bonafini explicó a los medios de comunicación los motivos de esta decisión:

[...] Lo sentimos así porque el enemigo ya no está en la Casa Rosada como en la dictadura, como con los anteriores presidentes, y a este gobierno ya no hay que resistirle sino acompañarlo, es un nuevo momento político con un proyecto latinoamericano que es como siempre lo soñamos [...] (Pagina 12, 25 de marzo de 2006).

Pero el acompañamiento de la AMDPM no significó una aceptación a ultranza de todas las orientaciones del gobierno. Al contrario de lo que los defensores de la idea de cooptación sostienen, el vínculo entre las inte- 
grantes de la AMDPM y el gobierno continuó presentando momentos de distancia y autonomía de las primeras respecto al último. Así, la AMDPM no dudó en mostrar sus diferencias con la propuesta de reconciliación con justicia, memoria y verdad, pronunciada por Néstor Kirchner, el 1 de Marzo de 2007 en la apertura del Periodo Ordinario de Sesiones del Congreso de la Nación ${ }^{18}$ o en pedir explicaciones por la intervención del Gobierno en el Instituto Nacional de Estadísticas y Censos (INDEC).

\section{Conclusiones}

A lo largo de este trabajo analizamos algunas de las transformaciones operadas en la Asociación Madres de Plaza de Mayo de Argentina durante la presidencia de Néstor Kirchner. En este sentido, se pudo observar el paulatino pasaje de una estrategia dominante de confrontación a una adhesión al gobierno nacional que llegó al poder en Argentina en 2003. La aparición de un gobierno que tomó como propias las demandas del MDHs generó en la AMDPM un cambio en la evaluación de la etapa y sus oportunidades políticas que explica en parte la nueva posición de estas.

Concomitantemente emergió una nueva clave interpretativa acerca del Estado que se caracterizó por transcurrir en dos niveles: uno instrumental y otro como posibilidad de construcción estratégica. En el primero de los casos, este comenzó a ser interpretado como la posibilidad de nuevos recursos para las tareas y para los organismos, en tanto el apoyo al gobierno nacional garantizaba un acompañamiento económico e institucional en sus iniciativas, nunca antes obtenido. Pero también significó vislumbrar al Estado como un espacio de resistencia "y construcción política” permitiendo la posibilidad de avanzar a un nivel de vinculación con el mismo nunca antes alcanzado. Esto último, se manifestó en una manera de concebir la vinculación con el Estado como parte de un proyecto político estratégico de largo plazo, desde donde fortalecer la lucha política contra un modelo de país y de sociedad, asociado a la idea de impunidad. Progresivamente comenzaron evaluar la etapa como el comienzo de la post impunidad y fueron identificándose con el gobierno.

Un aspecto de importancia que se observó, radica en que para la AMDPM comenzar a acompañar el gobierno, significó, además de una evaluación de las oportunidades políticas, el predominio de una lógica de acción afectiva en torno a la acción y la figura presidencial. Así, en torno a la figura de Néstor Kirchner, las madres construyeron un entramado de sentimientos y significados en torno a la política del presente y del pasado que las condujo a una identificación más amplia con el gobierno y las políticas gubernamentales. El nuevo gobierno fue interpretado en una clave familiar y esto produjo una compleja redefinición acerca de la etapa, que las condujo a combinar la idea de una ruptura con la impunidad con la reivindicación de un proyecto histórico que recuperaba los ideales de la generación de los 70 y que comenzó a ser percibido como una oportunidad que debían aprovechar. En este aspecto considerar la dimensión afectiva y los procesos de 
enmarcamiento nos permitió dar cuenta de la complejidad del trabajo con las tradiciones y los repertorios de lucha que realizó la AMDPM y aportar superando las explicaciones que reducen su accionar como meros destinatarios pasivos de interpelaciones o, peor aún, meros recursos. 


\section{Notas}

${ }^{1}$ Este artículo presenta resultados del proyecto de investigación: “¿Desde la resistencia a la victoria? El Movimiento de derechos humanos, el Estado y las luchas políticas en la Argentina (1983-2007)", actualmente en desarrollo para el Consejo Nacional de Investigaciones Científicas y Técnicas de Argentina (Res. 3446/12).

${ }^{2}$ Desde 1979 Hebe de Bonafini es la presidenta de la Asociación y su principal vocera. En adelante tomamos sus declaraciones como el discurso oficial de la Asociación.

${ }^{3}$ Por kirchnerismo entendemos el proyecto político que gobierna a la Argentina desde mayo de 2003, incluyendo las gestiones de Néstor Kirchner y de Cristina Fernández de Kirchner.

${ }^{4}$ En su formulación original Tarrow ha indicado que la estructura de oportunidades refiere a las dimensiones congruentes del entorno político que ofrecen incentivos para que la gente participe en acciones colectivas al afectar sus expectativas de éxito o fracaso (1997, p. 115).

${ }^{5}$ Uno de los aspectos impugnados por la AMDPM en relación a estos decretos radicó en que para ellas institucionalizaban la denominada "teoría de los dos demonios", al equiparar las acciones y responsabilidades de las organizaciones armadas con las de las Fuerzas Armadas.

${ }^{6}$ Se conoce como Juicio a las Juntas el proceso judicial realizado por la justicia civil (por oposición a la justicia militar) en la Argentina en abril de 1985, contra los integrantes de las tres primeras juntas militares de la dictadura autodenominada Proceso de Reorganización Nacional (1976-1983).

${ }^{7}$ La Ley de Punto Final ( $\left.{ }^{\circ} 23.492\right)$ fue una disposición legal promulgada en Argentina el 24 de diciembre de 1986. La misma estableció un plazo de caducidad de la acción penal (prescripción) contra los imputados como autores penalmente responsables de haber cometido el delito complejo de desaparición forzada de personas (que involucró detenciones ilegales, torturas y homicidios agravados o asesinatos) que tuvieron lugar durante la dictadura militar de 1976-1983. Por su parte la Ley de Obediencia Debida $\left(\mathrm{N}^{\circ} 23.521\right)$ estableció una presunción respecto de que los delitos cometidos por los miembros subordinados de las Fuerzas Armadas durante el Terrorismo de Estado y el autodenominado Proceso de Reorganización Nacional no eran punibles, por haber actuado en virtud de obedecer las órdenes emanadas de sus superiores.

${ }^{8}$ En 1986 se produjo la escisión de un grupo minoritario de la Asociación que se llamó Línea fundadora. En este trabajo utilizaremos la sigla AMDPM para referenciar únicamente a las madres enroladas en la Asociación Madres de Plaza de Mayo

\section{${ }^{9} \mathrm{Al}$ respecto véase Gorrini 2011(a) y 2011(b).}

${ }^{10}$ Durante el gobierno menemista las madres enroladas en la AMPDM fueron acusadas por Menem de traición a la patria, fueron objeto de numerosos atentados y sus demandas fueron denostadas por el presidente quien les pidió que "dejen de cargar con sus muertos, y olviden, que los muertos lloren a los muertos”. 
${ }^{11}$ Nombre de la coalición electoral conformada por la Unión Cívica Radical y el Frente del País Solidario en 1997 y que triunfó en las elecciones de 1999.

${ }^{12}$ Dichas jornadas estuvieron marcada por una violenta represión policial a las movilizaciones y manifestaciones populares que se produjeron a lo largo de todo el país y con un saldo de 39 muertos y decenas de heridos.

${ }^{13}$ Consigna utilizada durante las jornadas de 19 y 20 diciembre de 2001 por distintos actores sociales para expresar su desencanto con la dirigencia política.

${ }^{14} \mathrm{El}$ régimen electoral argentino establece que para ser electos Presidente y Vicepresidente, la fórmula más votada debe superar el $45 \%$ de los votos válidos o el $40 \%$ con una ventaja superior al $10 \%$ respecto de la segunda. De lo contrario, se realizará una segunda vuelta entre las dos fórmulas más votadas en primer vuelta, en la que serán proclamados Presidente y Vicepresidente los que obtengan un mayor número de votos.

${ }^{15}$ Esto fue manifestado por distintas integrantes de la asociación entrevistadas por el autor.

${ }^{16}$ Distintas integrantes de la AMDPM entrevistadas casi una década después todavía manifiestan la importancia de este acto.

${ }^{17}$ La Marcha de la resistencia es una movilización que realizaron ininterrumpidamente las integrantes de la AMDPM desde diciembre de 1981 en la Plaza de Mayo.

${ }^{18}$ Al respecto Hebe de Bonafini manifestó: [...] El discurso del Presidente estuvo excelente, fue un discurso donde no dejó nada por decir. Sólo que nosotras no compartimos el tema de la reconciliación con justicia, [...], Así que todo bien, estamos muy contentas, salvo este cachito, que por pequeño que parezca, a lo mejor muchos van a decir "ah, todo lo que habló, todo lo bueno que dijo, cómo las Madres van a cuestionar”. Es que no es pequeño, no es poquito, porque estamos hablando de nuestros hijos, de nuestros hijos y de nuestras hijas, de las torturas a las que fueron sometidos, de la muerte, de tirarlos vivos al río o al mar, de quemarlos vivos. No estamos hablando de una prisión, o de un preso. Estamos hablando de cosas muy graves. Así que con nosotras para la reconciliación que no cuente [...], (Hebe Pastor de Bonafini (2007, 1 de Marzo). 


\section{Bibliografía}

Andriotti Romanin, Enrique (2012) “De la resistencia a la integración. Las transformaciones de la Asociación Madres de Plaza de Mayo en la 'era Kirchner'”, Revista Estudios Políticos, N²1, Pag 35 - 54

Asociación Madres de Plaza de Mayo (1988, 1 de abril), “Carta a nuestros Hijos”, URL: www.madres.org/navegar/nav.php?idsitio=5\&idcat= 95\&pagina=15\&idindex=25\&b_frase $=$. Consultado el 18/2/13.

Asociación Madres de Plaza de Mayo (2002, 5 de junio), “Asociación Madres de Plaza de Mayo, Carta abierta al Presidente Eduardo Duhalde, a la dirigencia política, los senadores y diputados”, URL: http:// www.madres.org/navegar/nav.php?idsitio=5\&idcat=33\&pagina =4\&idindex=173\&b_frase=. Consultado el 18/2/13.

Barros, Mercedes (2009), "El discurso de los derechos humanos en la Argentina de la post-transición: un análisis discursivo de Alfonsín a Kirchner”, IX Congreso Nacional de Ciencias Políticas: Centros y periferias: equilibrios y asimetrías en las relaciones de poder, Ciudad de Santa Fe, 19 al 22 de agosto de 2009.

Borland, Elizabeth (2006), "Las Madres de Plaza de Mayo en la era neoliberal: ampliando objetivos para unir el presente el pasado y el futuro”, Colombia internacional, 63, pp. 130 - 147.

Braslavsky, Guido (2009), Enemigos íntimos. Los militares y Kirchner, Sudamericana, Buenos Aires.

D’Alessandro, Martin (1998), "Los movimientos sociales en la transición democrática. El caso de las Madres de Plaza de Mayo: sentimiento y discurso”, América latina hoy: Revista de Ciencias Sociales, 20, pp. 41-46.

Dobles Oropeza, Ignacio (2009), Memorias del dolor, las comisiones de verdad en América Latina, Arlequín, Costa Rica.

Gamson, William (1992a), Talking Politics, Cambridge University Press, Nueva York.

Gamson, William (1992b), “The Social Psychology of Collective Action”, en: Morris, Aldon D. y Mueller, Carol (eds), Frontiers in Social Movement Theory, Yale University Press, New Haven.

Gasulla, Luis (2012), El negocio de los derechos humanos, Sudamericana, Buenos Aires.

Goodwin, Jeff; Jasper , James y Francesca Polletta (2000),"Return of the Repressed: The Fall and Rise of Emotions in Social Movement Theory”, Mobilization, núm. 5, pp. 65-82. 
Goffman, Erving (2006), Frame Analysis, Centro de Investigaciones Sociológicas, Madrid.

Gorini, Ulises (2011a), La rebelión de las madres. Historia de las Madres de Plaza de Mayo (1976-1983), La página, Buenos Aires.

Idem (2011b), La otra lucha. Historia de las Madres de Plaza de Mayo (1976-1983), La página, Buenos Aires.

Gould, Deborah (2009), Moving Politics, University of Chicago Press, Chicago.

Jasper, James (2012) “¿De la estructura a la acción? La teoría de los movimientos sociales después de los grandes paradigmas”, Sociológica, año 27, número 75, enero-abril, pp. 7-48.

Nussbaum, Martha C. (2001), Upheavals of Thought, Cambridge University Press, Cambridge.

Pastor de Bonafini, Hebe (1998, 10 de diciembre), "Discurso clausura $18^{\circ}$ Marcha de la Resistencia: Es una obligación de ustedes cumplir el sueño de los 30.000”, URL: http://www.madres.org/navegar/ nav.php?idsitio=5\&idcat=96\&idindex=25. Consultado el 18/2/13.

Idem (1998, 24 de marzo), "Festival en el estadio de Rosario Central”, URL: http://www.madres.org/navegar/nav.php?idsitio=5\&idcat =96\&pagina=1\&idindex=173\&b_frase=. Consultado el 18/2/13.

Idem (2004, 2 de abril), "Reportaje, la izquierda nunca entendió a las madres”, URL: http://www.lafogata.org/opiniones/aiz_hebe.htm. Consultado el 18/2/13.

Idem (2007, 1 de marzo), “Discurso en ronda de los jueves”, URL: en:// w w w. madres.org/navegar/nav.php? id siti $o=5 \&$ idcat $=$ 82\&pagina=21\&idindex=25\&b_frase $=$. Consultado el 18/2/13.

Idem (2010, 28 de octubre), “Carta a Nestor Kirchner”, URL: http:// www.larazon.com.ar/actualidad/Hebe-Bonafini-llegaste-volvioalegria_0_180900085.html. Consultado el 18/2/13.

Néstor Kirchner (2003), Discurso de asunción de 25 de mayo de 2003, Biblioteca del Congreso de la Nación Argentina, Buenos Aires.

Idem (2004), Discurso de 24 de marzo con motivo de Creación del Museo de la Memoria (Ex ESMA), Biblioteca del Congreso de la Nación Argentina, Buenos Aires.

Idem (2006), Palabras del presidente Néstor Kirchner, en el acto de conmemoración del Día nacional de la memoria por la verdad y la justicia, cele- 
brado en el colegio militar de la nación, Biblioteca del Congreso de la Nación Argentina, Buenos Aires.

Mayorga Rojel, Alberto Javier y del Valle Rojas, Carlos (2010), “La representación del Estado en el discurso de la Asociación Madres de la Plaza de Mayo en Argentina”, Polis [En línea], 26 | 2010, Puesto en línea el 20 abril 2012, consultado el 04 marzo 2013.

McAdam, Douglas (1982), Political Process and the Development of Black Insurgency, University of Chicago Press, Chicago.

Montero, Ana Soledad (2013), ¡Y al final un día volvimos! Los usos de la memoria en el discurso Kirchnerista, Prometeo, Buenos Aires.

Morales Virginia (2012), “Asociación Madres de Plaza de Mayo: kirchnerismo y resignificación”, en: Barros, Mercedes; Daín Andrés y Virginia Morales (eds.), Escritos K, Eduvin, Villa María.

Retamozo, Martín (2011), “Movimientos sociales, política y hegemonía en Argentina “, Polis [En línea], 28, consultado el 03 marzo 2013. URL: http:/ /polis.revues.org/1249; DOI : 10.4000/polis.1249.

Romero, Luis Alberto (2011), Breve Historia Contemporánea de la Argentina (1916-2010), Fondo de Cultura Económica, Buenos Aires.

Snow, David y Benford, Robert (1992), "Master Frames and cicles of protest”, en: Morris, Aldon y McClurc Mueller, Carol (eds.), Fronters in Social Movement Theory. Yale University Press, Connecticut.

Sondereguer, María (1985), “Aparición con vida, el Movimiento de derechos humanos en la Argentina”, en: Jelin, Elizabeth (ed.), Los nuevos movimientos sociales/ tomo 2, CEAL, Buenos Aires.

Tarrow, Sydney (1997), El poder en movimiento: los movimientos sociales, la acción colectiva y la política, Editorial Alianza, Buenos Aires.

Zald, Mayer. (1999), “Cultura, ideología y creación de marcos estratégicos”, en: Mc Adam, Douglas; McCarthy, Jhon y Zald, Mayer (eds.), Movimientos sociales, perspectivas comparadas, Istmo, Madrid.

Recibido: 22.03.2013

Aceptado: 15.03.2014 